\title{
TEACHING AND LEARNING
}

\section{Reflections of a Librarian - Teaching Through a Crisis}

NANDI PRINCE

New York City College of Technology, Brooklyn, NY

nprince@citytech.cuny.edu

What helps you persevere is your resilience and commitment.

-Roy T. Bennett, The Light in the Heart

The coronavirus pandemic has tested the resilience of faculty and students around the world. In March 2020, the pandemic necessitated a sudden pivot to virtual instruction at many educational institutions. Transforming an in-person course to an online platform during the ongoing health crisis was challenging for all (Hensley, Avila-Medina, Gillespie, Lee, Masonheimer, Nagpal, Perry, Varzeas, \& You, 2020). My college had two breaks; the first break sent students home in order to flatten the curve, and the second bridged the digital divide when devices were distributed to students. When we resumed the semester, I realized that my students were having a passive learning experience, which I felt compelled to change. My philosophy is to teach with compassion because it fosters an atmosphere in which the students' needs are primary. Student-centered approaches steered my pedagogical practices to address the ongoing changes during COVID-19. I launched a survey via the Blackboard content learning management system course site to 1) garner students' feedback and ascertain technology needs; 2) perform a critical in-semester evaluation of how students engaged in the course; and 3) retool and adopt different methodologies to preserve or improve the cultivated familiarity that students expected from their on-campus classes. Ninety-five percent of students responded to the survey.

One adjustment I experienced was teaching to blank screens in Zoom with video cameras off, which was later sanctioned by an institutional policy developed during COVID-19. I certainly understood students keeping their cameras off, because they were being asked to let the professor and other students into their home environment. Also, technical issues arose in some cases due to insufficient bandwidth to support camera use. Unfortunately, the blank screens hampered relationship building during the instruction session. I implemented strategies to overcome the barrier of being unable to read student body language and facial expressions when key concepts were taught. One strategy I implemented was to incorporate group activity into every synchronous session in order to build peer collaboration and to provide students with an opportunity to have small group interaction with the professor.

There was concern for the wellness and mental health of my students as they were pursuing academic continuity and dealing with the effects of COVID-19 (Hensley et al., 2020). Many of their campus community support services and resources were suspended or interrupted, and this resulted in trying new approaches that met the course learning outcomes (Chen, 2020). I experimented with assignment formats, converted some written assignments to audio and video work, and personalized content to their experiences. Students enjoyed using their mobile phones to make videos about social issues and being content creators of information in the research course (Smith \& Narayan, 2019). Students were more mindful of evaluating sources and placed more emphasis on including sources that 
Ticker: The Academic Business Librarianship Review, 5:2 (2021)

were exceptionally reliable in the video assignment. This represented a shift in their information-seeking behavior compared to when they completed research for written assignments in past semesters. I administered mid- and end-of-semester assessments using the survey tool within Blackboard to encourage reflection on their digital experiences with the course. I plan to continue with these new tools, as the assessments showed that students responded favorably to their use. Teaching through a pandemic while employing new techniques for instructional delivery continues to rejuvenate my instruction and build upon my compassionate approach for students' academic success. 
Ticker: The Academic Business Librarianship Review, 5:2 (2021)

http://dx.doi.org/10.3998/ticker.16481003.0005.210

(C)2021 Nandi Prince

\section{References}

Chen, C. W. (2020). Learning through participation: A case study on the affordances of making YouTube tutorial videos. JALT CALL Journal, 16(1), 51-67.

Hensley, L., Avila-Medina, F., Gillespie, T., Hye Won Lee, Masonheimer, A., Nagpal, M., Perry, A., Varzeas, K., \& Ya You. (2020). Compassionate teaching during COVID-19: Key approaches in a college success course. Learning Assistance Review (TLAR), 25, 349-360.

Smith, L.-H., \& Narayan, A. (2019). Teaching compassionate research in a global classroom. Teaching in Higher Education, 24(2), 248-257. https://doi.org/10.1080/13562517.2018.1541882 